\title{
The molecular genetics of Alport syndrome: report of two workshops
}

Alport syndrome (AS), a hereditary nephritis progressing to end stage renal failure in males, with sensorineural deafness, anterior lenticonus, and macular flecks, represents a significant medicoeconomic burden. ${ }^{1}$ Molecular genetics has now begun to unravel its complexities, although these are still far from resolved.

Two recent international workshops have discussed the latest developments. Last August, a meeting at Oulu (International Workshop on Alport's Syndrome, Oulu, Finland, 22 to 24 August 1991) set out to draw meaningful correlations between the different mutations characterised to date and the resulting phenotypes, and this was followed in October by a further workshop in Washington, DC (Workshop on Hereditary Kidney Disease, 8th International Congress of Human Genetics, Washington DC, October 1991).

Investigation of AS has not been straightforward. Over 50 years ago Alport ${ }^{2}$ described a three generation family with haematuria and deafness, showing most signs of the syndrome later named after him, and several large kindreds have subsequently been described, with varying patterns of inheritance. ${ }^{3-5}$

Three groups independently localised the AS gene to Xq21-q22. ${ }^{6-8}$ AS had long been thought to affect primarily basement membrane collagen, as the glomerular basement membrane (GBM) in AS is grossly disordered. GBM mainly consists of collagen type IV, but the two component chains identified first ( $\alpha$ I(IV) and $\alpha 2$ (IV)) mapped to chromosome $13 .^{9}$ Only later did it emerge that other rare chains were involved in collagen IV, ${ }^{10}$ and not until 1990 was one of these, $\alpha 5$ (IV), independently cloned by two groups from Oulu ${ }^{112}$ and the gene mapped to the AS region on the $\mathrm{X}$ chromosome.

Tryggvason and his international collaborators then clinched matters by reporting mutations in the $\alpha 5$ (IV) gene in three AS kindreds. ${ }^{13}$ Details of 30 or so independent mutations which have been characterised by several groups to date were presented at Oulu. The organisers aimed to correlate these different mutations with the resulting phenotype, and this led to the establishment of an international consortium to exchange information on the gene and its mutants.

Following Oulu, the Washington workshop covered a number of other disorders, including polycystic kidney disease, Lowe syndrome, and von Hippel-Lindau disease, but Alport syndrome received substantial attention. One interesting subject raised was the immune response to renal transplantation; $14 \mathrm{AS}$ patients who developed anti-GBM antibodies leading to graft rejection have now been reported. ${ }^{14}$ Kashtan (Minneapolis) postulated that major rearrangements within the $\alpha 5$ (IV) gene might be more likely to lead to anti-GBM nephritis, with subsequent graft rejection, but this is not yet clear. A further complicating factor was discussed by Hudson (Kansas), who presented his findings on the specificity of anti-GBM antibodies eluted from an AS patient's rejected graft. The alloantibodies reacted mainly with dimer subunits of the NCI domain of collagen IV, identical to those reacting with Goodpasture (GP) antibodies, and have been chemically identified as derived from the $\alpha 3$ chain of collagen IV (mapped to chromosome 2). This means that GBM collagen antigenicity is altered in some AS patients, which may reflect either the absence of the $\alpha 3$ chain, or the exposure of a new structural epitope on this chain. These findings, together with evidence that some AS patients fail to bind the GP antibody in their native kidneys, and that antibasement membrane autoantibodies produced by GP patients sometimes fail to stain glomeruli in AS kidneys, ${ }^{15}$ strongly suggest that the $\alpha 3$ chain, as well as the newly characterised $\alpha 5$ chain, is involved in the primary pathology.

'Alport syndrome' has been used to label many sorts of hereditary nephritis, and some remarkably imaginative theories of inheritance have been put forward. Barker (Salt Lake City) dismissed some of these, and reviewed others, at the Oulu workshop. There has been no general agreement on the frequency of autosomal versions, if indeed they exist. The main question is: are all $\mathrm{X}$ linked cases attributable to the $\alpha 5$ (IV) gene locus, or is there another type IV collagen gene on the $\mathrm{X}$ chromosome? Also at Oulu, Tryggvason presented the most persuasive hint yet that a second $\mathrm{X}$ linked gene exists, a family with a mutation in the $\mathrm{X}$ linked gene but with no hearing impairment. The basement membrane collagen chain genes show interesting groupings: $\alpha 1$ and $\alpha 2$ map close together on chromosome $13^{9}$ and $\alpha 3$ and $\alpha 4$ have now been mapped close together on 2q by Reeders (New Haven), who speculated that there may also be an undiscovered $\alpha 6$ on the $\mathrm{X}$ chromosome, close to $\alpha 5$.

Mapping and cloning genes generates publicity, but is only the first step towards understanding a gene's function. Precise definition of mutations, the next step, brings immediate practical benefits, allowing precise carrier detection and prenatal diagnosis. In addition, defining individual mutations and correlating 
them with the phenotype provides information on critical domains of the gene and its product, the tissues where it is expressed, and the range of effects of disordered gene function (different mutations presumably affecting the strength of the collagen network in different ways). The mass of new data arising from the two workshops has strengthened the idea that the connection between the apparently disparate organs affected may lie in the particular collagen chains from which they are constructed.

Our knowledge will expand rapidly as more mutations causing AS are characterised. So far, it appears that only some 10 to $15 \%$ of mutations (mostly reported at Oulu) are the result of large, easily detectable gene rearrangements. ${ }^{1316}$ Defining the rest will be less easy, although detailed information on cDNA sequence and genomic structure (Tryggvason, Oulu) allows 'mutation scanning' techniques such as chemical cleavage of mismatched DNA, ${ }^{17}$ denaturing gradient gel electrophoresis, ${ }^{18}$ single strand conformational polymorphism, ${ }^{19}$ or RNAse cleavage ${ }^{20}$ to be used. These techniques compare the sequence of DNA under test with a control, and highlight any base mismatches for more detailed characterisation. Several groups are applying these to the AS gene, and the main long term benefit to emerge from these two meetings may be the international exchange of information on mutations as they are defined.

The last three years have seen many significant advances in the understanding of the molecular pathology of AS, but important questions remain unanswered. Is AS one disorder or many? Eleven subtypes (discussed by Atkin, Salt Lake City, at Oulu) have been discerned, but whether these correspond to the effects of different genes, or allelic mutations in one gene, is unresolved. However, we should soon know if the 'splitters' or the 'lumpers' will carry the day.

FRANCES FLINTER
MARTIN BOBROW
Paediatric Research Unit,
Division of Medical and Molecular Genetics,
UMDS, Guy's Hospital,
London SE1 $9 R T$.

1 Broyer M, Brunner FP, Brynger J, et al. Demography of dialysis and transplantation in Europe. Report from the dialysis and transplantation in Europe. Report from the Nuropean Dialysis and Transplant A

2 Alport AC. Hereditary familial congenital haemorrhagic nephrt AC. Hereditary familial $B M \mathcal{1}$ 1927;i:504-6.
nephritis.

3 Penkoff GT, Stephens FE, Dolowitz DA, et al. A clinical study of hereditary interstitial pyelonephritis. Arch Intern
sturitzal Med 1951;88:191-200.

4 Grunfeld JP. The clinical spectrum of hereditary nephritis. Kidney Int 1985;27:83-92

5 Flinter FA, Cameron JS, Chantler C, et al. Genetics of classic Alport's syndrome. Lancet 1988;ii:1005-7.

6 Atkin CL, Hasstedt SJ, Menlove L, et al. Mapping of Alport syndrome to the long arm of the $\mathrm{X}$ chromosome. Am $\mathcal{F}$ Hum Genet 1988;42:249-55.

7 Brunner H, Schroder C, van Bennekom C, et al. Localization of the gene for $\mathrm{X}$-linked Alport syndrome. Kidney In 1988;34:507-10.

8 Flinter FA, Abbs S, Bobrow M. Localization of the gene for classic Alport syndrome. Genomics 1989;4:335-8.

9 Griffin CA, Emanuel BS, Hansen JR, et al. Human collagen genes encoding basement membrane $\alpha 2$ (IV) chains map to the distal long arm of chromosome 13. Proc Natl Acad Sci USA 1987;84:512-6.

10 Butkowski RJ, Langeveld JPM, Wieslander J, et al. Localisation of the Goodpasture epitope to a novel chain of basement membrane collagen. $f$ Biol Chem 1987; 262:7874-7.

11 Hostikka SL, Eddy RL, Byers MG, et al. Identification of a distinct type IV collagen $\alpha$ chain with restricted kidney distribution and assignment of its gene to the locus of $\mathbf{X}$ chromosome-linked Alport syndrome. Proc Natl Acad Sci USA 1990;87:1606-10.

12 Pihlajaniemi T, Pohjolainen E-R, Myers JC. Complete primary structure of the triple-helical region and the carboxyl-terminal domain of a new type IV collagen chain, $\alpha$ (IV). F Biol Chem 1990;265:13758-66.

13 Barker D, Hostikka SL, Zhou J, et al. Identification of mutations in the COL4A5 collagen gene in Alport syndrome. Science 1990;248:1224-7.

14 Cameron JS. Recurrent primary disease and de novo nephritis following renal transplantation. Pediatr Nephrol 1991;5:412-21.

15 Fleming SJ, Savage COS, McWilliam LJ, et al. Antiglomerular basement membrane antibody mediated nephritis complicating transplantation in a patient with Alport syndrome. Transplantation 1988;46:857-9.

16 Boye $E$, Vetrie $D$, Flinter $F$, et al. Major rearrangements in the $\alpha 5$ (IV) collagen gene in three patients with Alport's syndrome. Genomics 1991;11:1125-32.

17 Cotton RGH, Rodrigues NR, Campbell RD. Reactivity of cytosine and thymine in single-base-pair mismatches with hydroxylamine and osmium tetroxide. Proc Natl Acad Sci hydroxylamine and osmium

18 Scheffield VC, Cox DR, Lerman LS, et al. Attachment of a 40 base pair $G+C$ rich sequence (GC clamp) to genomic DNA fragments by the polymerase chain reaction results in improved detection of single base changes. Proc Natl Acad Sci USA 1989;86:232-6.

19 Orita M, Iwahana H, Kanazawa $H$, et al. Detection of Orita $\mathrm{M}$, Iwahana $\mathrm{H}$, Kanazawa $\mathrm{H}$, et al. Detection of
polymorphisms of human DNA by gel electrophoresis as single strand conformation polymorphism. Proc Nat Acad Sci USA 1989;86:2766-70.

20 Myers RM, Larin Z, Maniatis T. Detection of single base substitutions by ribonuclease cleavage at mismatches in RNA:DNA duplexes. Science 1985;230:1242-6. 